\title{
Posttranslational Modification of Sox11 Regulates RGC Survival and Axon Regeneration
}

\author{
ํ. Kun-Che Chang, ${ }^{1}$ Minjuan Bian, ${ }^{1}$ Xin Xia, ${ }^{1}$ Ankush Madaan, ${ }^{1}$ Catalina Sun, ${ }^{1}$ Qizhao Wang, ${ }^{1}$ Liang Li, ${ }^{1}$ \\ Michael Nahmou, ${ }^{1}$ Takahiko Noro, ${ }^{1,2}$ 'Satoshi Yokota, ${ }^{1}$ Joana Galvao, ${ }^{1}$ Alexander Kreymerman, ${ }^{1}$ \\ Bogdan Tanasa, ${ }^{1}$ 'Pang Hu, ${ }^{1}$ and Jeffrey L. Goldberg ${ }^{1}$
}

https://doi.org/10.1523/ENEURO.0358-20.2020

${ }^{1}$ Spencer Center for Vision Research, Byers Eye Institute, School of Medicine, Stanford University, Palo Alto, CA 94304 and ${ }^{2}$ Department of Ophthalmology, The Jikei University School of Medicine, Tokyo 105-8461, Japan

\begin{abstract}
The failure of adult CNS neurons to survive and regenerate their axons after injury or in neurodegenerative disease remains a major target for basic and clinical neuroscience. Recent data demonstrated in the adult mouse that exogenous expression of Sry-related high-mobility-box 11 (Sox11) promotes optic nerve regeneration after optic nerve injury but exacerbates the death of a subset of retinal ganglion cells (RGCs), $\alpha$-RGCs. During development, Sox11 is required for RGC differentiation from retinal progenitor cells (RPCs), and we found that mutation of a single residue to prevent SUMOylation at lysine 91 (K91) increased Sox11 nuclear localization and RGC differentiation in vitro. Here, we explored whether this Sox11 manipulation similarly has stronger effects on RGC survival and optic nerve regeneration. In vitro, we found that non-SUMOylatable Sox $11^{\mathrm{K} 91 \mathrm{~A}}$ leads to RGC death and suppresses axon outgrowth in primary neurons. We furthermore found that Sox $11^{\mathrm{K} 91 \mathrm{~A}}$ more strongly promotes axon regeneration but also increases RGC death after optic nerve injury in vivo in the adult mouse. RNA sequence (RNA-seq) data showed that Sox11 and Sox11 ${ }^{\mathrm{K} 91 \mathrm{~A}}$ increase the expression of key signaling pathway genes associated with axon growth and regeneration but downregulated Spp1 and Opn4 expression in RGC cultures, consistent with negatively regulating the survival of $\alpha$-RGCs and ipRGCs. Thus, Sox11 and its SUMOylation site at K91 regulate gene expression, survival and axon growth in RGCs, and may be explored further as potential regenerative therapies for optic neuropathy.
\end{abstract}

Key words: optic nerve regeneration; retinal ganglion cell; Sox11; SUMOylation

\section{Significance Statement}

Sry-related high-mobility-box 11 (Sox11) expression promotes optic nerve regeneration but also increases retinal ganglion cell (RGC) death after optic nerve injury. Here, we demonstrate that mutation of a single SUMOylation site on Sox11 (Sox11 ${ }^{\mathrm{K} 91 \mathrm{~A}}$ ) leads to stronger effects in vivo. RNA sequencing (RNA-seq) analysis reveals that Sox 11 and Sox $11^{\mathrm{K} 91 \mathrm{~A}}$ differentially regulate downstream gene expression related to axon growth and guidance. Understanding these effects of posttranslational modification of Sox11 in regulating regeneration in vivo suggests a potent therapeutic strategy for vision restoration in optic neuropathies.

\section{Introduction}

Restoring neuronal connections and function in degenerative diseases and after injury in the CNS is a critical goal for neuroscience and has been investigated for decades, with only a handful of approaches showing promise

Received August 16, 2020; accepted December 22, 2020; First published January 13, 2021.

The authors declare no competing financial interests. in preclinical models. In the visual system, retinal ganglion cells (RGCs), projection neurons responsible for transmitting vision from the eye to the brain, have been a major target for research as RGCs undergo cell death and axon

Author contributions: K.-C.C. designed research; K.-C.C., M.B., X.X., A.M., C.S., Q.W., L.L., M.N., T.N., S.Y., and J.G. performed research; Q.W., L.L., and Y.H. contributed unpublished reagents/analytic tools; K.-C.C., M.B., X.X., and B.T. analyzed data; K.-C.C., A.K., and J.L.G. wrote the paper. 
degeneration in patients suffering from glaucoma or other optic neuropathies (Goldberg et al., 2016). Thus, optic nerve models are relevant for studying CNS axon regeneration and have pointed to a number of discoveries of signaling pathways implicated in survival and axon regeneration (Benowitz et al., 2017).

A number of transcription factors that play a role in RGC differentiation during early development also have been implicated in regulating survival or axon regeneration in the adult. For example, Pou4f2 contributes to late differentiation of RGCs in the early postnatal period (Badea et al., 2009) and promotes RGC survival in an ocular hypertension model of glaucoma (Stankowska et al., 2015). We and others have shown that Sry-related high-mobility-box4 and 11 (Sox4 an Sox11) are required for RGC differentiation (Jiang et al., 2013; Chang and Hertz, 2017; Chang et al., 2017, 2019; Kuwajima et al., 2017). Increased Sox11 expression has also been shown to promote RGC survival after optic nerve crush (Struebing et al., 2017), and more recently, overexpression of Sox 11 was reported to promote axon regeneration but also lead to increased death of $\alpha$-RGCs (Norsworthy et al., 2017). Thus, more work is required to identify how to target Sox 11 for vision restoration while limiting cell death.

Posttranslational modifications such as the addition of the small ubiquitin-related modifier (SUMO) have been show to plays an critical role in regulating Sox11 nuclear localization and gene regulation (Gill, 2005; Roger et al., 2010). We demonstrated that Sox11 SUMOylation at lysine residue 91 (K91) suppressed its nuclear translocation from the cytoplasm; site mutation of Sox11 to prevent SUMOylation led to higher nuclear localization and to an increase in RGC differentiation from retinal progenitor cells (Chang et al., 2017). However, whether Sox11 SUMOylation at K91 is critical for Sox11's effects on RGC survival, and axon regeneration was still unknown. Here, we studied this question in vitro and in vivo, and find that as in RGC development, this K91 site is a major regulator of survival and axon growth in the adult. We extend this work using RNA sequencing (RNA-seq) of Sox11-expressing or Sox $11^{\mathrm{K} 91 \mathrm{~A}}$-expressing RGCs to identify the differentially regulated signaling pathways attributable to Sox 11 and Sox $11^{\mathrm{K} 91 \mathrm{~A}}$. Overall, our results expand on mechanisms of gene regulation contributing to RGC survival and axon regeneration by manipulation of Sox 11 .

This study was supported by the Gilbert Family Foundation, the BrightFocus Foundation, National Eye Institute Grants P30-EY026877 and F32-EY029137, and the Research to Prevent Blindness, Inc.

K-C Chang's present address: Department of Ophthalmology, Louis J. Fox Center for Vision Restoration, University of Pittsburgh School of Medicine, Pittsburgh, Pennsylvania 15213.

Correspondence should be addressed to Kun-Che Chang at kunche@ stanford.edu or Jeffrey L. Goldberg at jlgjournals@gmail.com.

https://doi.org/10.1523/ENEURO.0358-20.2020

Copyright $\odot 2021$ Chang et al.

This is an open-access article distributed under the terms of the Creative Commons Attribution 4.0 International license, which permits unrestricted use, distribution and reproduction in any medium provided that the original work is properly attributed.

\section{Materials and Methods}

\section{Animals}

All use of animals conformed to the Association for Research in Vision and Ophthalmology (ARVO) Statement for the Use of Animals in Research, and was approved by the Institutional Animal Care and Use Committee (IACUC) and the Institutional Biosafety Committee of Stanford University. C57BL/6 mice both male and female of varying ages were obtained from Charles River.

\section{Adeno-associated virus (AAV) preparation}

Plasmids for Sox11-IRES-EGFP, Sox $11^{\mathrm{K} 91 \mathrm{~A}}$-IRES-EGFP, and control EGFP were obtained from VectorBuilder. AAV production was performed at the Stanford Vision Research Core (PI, Yang Hu) as previously described (Wang et al., 2020). Briefly, AAV plasmids were co-transfected with pAAV2 (pACG2)-RC triple mutant (Y444, 500, 730F) and pHelper plasmid (Strategene) into human embryonic kidney 293 (HEK 293) cells. The AAVs were purified using $40 \%$ polyethylene glycol. The AAV titers were determined by quantitative realtime PCR (qRT-PCR) and diluted to $2 \times 10^{13}$ vector genome (vg) $/ \mathrm{ml}$ stocks and stored at $-80^{\circ} \mathrm{C}$ until use.

\section{Cell line cultures and Western blotting}

HEK 293 cells were cultured in DMEM medium (Corning) containing fetal bovine serum (FBS; 10\%, Invitrogen) and penicillin/streptomycin (PS; 1\%, Thermo Fisher Scientific) on six-well tissue culture plates. Cells were manually passaged approximately every $3 \mathrm{~d}$ or until $\sim 80 \%$ confluence. Cell lines were kept in $37^{\circ} \mathrm{C}$ incubation at $5 \% \mathrm{CO}_{2}$.

For Western blotting, protein samples were collected in Laemmli sample buffer (Thermo Fischer Scientific) and heated to $100^{\circ} \mathrm{C}$ for $10 \mathrm{~min}$. Proteins were resolved by SDS-PAGE (Bio-Rad) and transferred to PVDF membranes using a semi-dry blotter (Bio-Rad). Membranes were blocked with 5\% non-fat milk and then probed with primary antibodies rabbit anti-Sox11 (1:1000, Abcam) or anti-GAPDH (1:2000, Cell Signaling Technology) overnight at $4^{\circ} \mathrm{C}$. Membranes were washed and probed with secondary antibodies conjugated to horseradish peroxidase (Millipore), and developed with the Western Blot Substrate kit (Thermo Fischer Scientific) by detecting chemiluminescence using the ChemiDoc XRS+ imaging system (Bio-Rad).

\section{RGC culture and neurite outgrowth assays}

Mouse RGCs from postnatal day (P2) pups were purified by immunopanning using CD90.1 as described previously (Barres et al., 1988). RGCs were plated onto PDL/ laminin-coated tissue culture plates in Full Sato (FS) medium including forskolin (5 mm), BDNF (50 ng/ml), and CNTF $(10 \mathrm{ng} / \mathrm{ml})$ as described previously (Meyer-Franke et al., 1995). Plating densities were $2.5 \times 10^{3} \mathrm{RGCs} /$ well in 24-well plates for neurite outgrowth assay, or $2.5 \times 10^{5}$ RGCs/well in six-well plates for RNA-seq and Western blot assays.

For viral transduction in the neurite outgrowth assay, Sox11 and Sox $11^{\mathrm{K} 91 \mathrm{~A}}$ AAV2 viruses were diluted to $2 \times 10^{11} \mathrm{vg} / \mathrm{ml}$ 

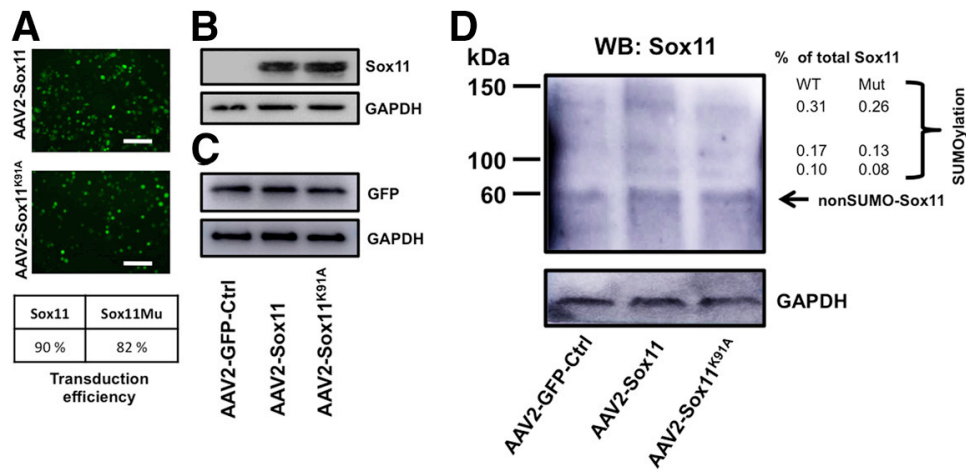

Figure 1. Point mutation of Sox11 lysine 91 to alanine (Sox $\left.11^{\mathrm{K} 91 \mathrm{~A}}\right)$ attenuates expression of SUMOylated isoforms. $\boldsymbol{A}, \boldsymbol{B}, \mathrm{HEK}$ cells $\left(2 \times 10^{5}\right.$ cells/well) and $(C)$ hippocampal neurons $\left(10^{6}\right.$ cells/well) were infected with GFP control, Sox 11 , and Sox11 ${ }^{\mathrm{k} 91 \mathrm{~A}}$ AAV2 viruses. Fluorescence imaging suggested similar expression levels between Sox11 viral vectors $(\boldsymbol{A})$ and Sox 11 and Sox $11^{\mathrm{K} 91 \mathrm{~A}}$ protein expression were also similar when assayed by Western blotting $(\boldsymbol{B}, \boldsymbol{C})$. $\boldsymbol{D}$, For SUMOylation detection, P2 RGCs $\left(5 \times 10^{5}\right.$ cells/well) were infected with GFP-conjugated control, Sox11, and Sox $11^{\mathrm{K} 91 \mathrm{~A}}$ viruses. Quantification of higher molecular weight bands corresponding to total Sox11 protein was detected by Western blotting against Sox11, which detected both endogenous and mutant protein. Scale bar: $100 \mu \mathrm{m}$.

in medium and added at a multiplicity of infection (MOI) of $\sim 10^{5} \mathrm{vg} /$ cell overnight, and then changed into fresh culture medium for another $2 \mathrm{~d}$. RGCs were immunstained with antibodies against $\beta$-III-tubulin. Briefly,equal amount $37^{\circ} \mathrm{C}$ $4 \%$ paraformaldehyde (PFA) was added into the medium for $20 \mathrm{~min}$ for fixation. The neurites were stained with mouse anti- $\beta$-III-tubulin antibody E7 (1:500, hybridoma from Developmental Studies Hybridoma Bank) overnight at $4^{\circ} \mathrm{C}$ and probed with Alexa Fluor 647-tagged anti-mouse antibody (1:500; Life technologies) for $2 \mathrm{~h}$ at room temperature. $\mathrm{GFP}^{+}$and $\mathrm{DAPI}^{+}$RGCs were imaged on a Zeiss Axio Observer inverted microscope using a $10 \times$ objective to measure neurite outgrowth and survival, respectively. Total length of neurites per cell (30-60 cells average per condition per experiment) was measured using ImageJ Simple Neurite Tracer.

\section{AAV transduction and optic nerve crush in vivo}

To express Sox11 or Sox $11^{\mathrm{K} 91 \mathrm{~A}}$ in vivo, both eyes of C57BL/6 mice were injected intravitreally with $2 \mu \mathrm{l}$ of AAV2luc-EGFP or AAV2-Sox11-EGFP or AAV2-Sox11 ${ }^{\mathrm{K} 91 \mathrm{~A}}$-EGFP at P28, as previous described (Boczek et al., 2019). For optic nerve crush, two weeks after virus injection, the left optic nerve was exposed from outer canthus and pinched for $5 \mathrm{~s}$ with a Dumont Fine Science Tools \#5 self-closing forceps $\sim 1.5 \mathrm{~mm}$ behind the globe. All optic nerve crush procedures were performed masked to the viral vector treatment. At day 12 after optic nerve crush, 2- $\mu$ l cholera toxin subunit B (CTB)-conjugated Alexa Fluor 555 (CTB-555, $5 \mu \mathrm{g} / \mu \mathrm{l}$; Invitrogen) was intravitreally injected as an anterograde tracer to visualize regenerating axons; animals were euthanized $2 \mathrm{~d}$ later, 14 days after crush after optic nerve crush. Optic nerves were dissected and fixed in 4\% PFA for $1 \mathrm{~h}$ and subsequently washed in PBS. Optic nerves were then incubated in $15 \%$ sucrose at $4^{\circ} \mathrm{C}$ overnight and then in $30 \%$ sucrose at $4^{\circ} \mathrm{C}$ overnight before mounting in Optimal Cutting Temperature mounting medium (Thermo Fisher Scientific) before cutting longitudinal $12-\mu \mathrm{m}$-thick cryosections. Optic nerve sections were imaged and analyzed as previously described (Cameron et al., 2020). Briefly, the number of $\mathrm{CTB}^{+}$axons within every $250 \mu \mathrm{m}$ from the crush site were manually counted to the end of the longest regenerating axons. Total regenerating axons per optic nerve were calculated using the formula as previously described (Bei et al., 2016).

For RGC survival analysis, retinas were dissected and fixed in $4 \%$ PFA for $1 \mathrm{~h}$, then permeabilized with $3 \%$ Triton X-100 (Sigma) and 1.5\% Tween 20 (Sigma) for another hour, blocked with $10 \%$ normal goat serum (NGS) in PBS for $1 \mathrm{~h}$, and then incubated with a rabbit polyclonal anti-RBPMS primary antibody (1:500; PhosphoSolution) overnight at $4^{\circ} \mathrm{C}$. Retina samples were washed three times, ten minutes each, with PBS and incubated with rabbit polyclonal Alexa Fluor 647tagged anti-rabbit antibody (1:500; Life technologies) overnight. The explants were then washed twice, ten minutes each, stained with DAPI (1:5000 in PBS) for $15 \mathrm{~min}$, washed twice $10 \mathrm{~min}$ each, and sealed under $1.5-\mathrm{mm}$ coverslips with anti-fade mounting medium (ProLong Gold, Life Technologies) before imaging via confocal microscopy (Zeiss). The retinas were divided into four quadrants, and one digital micrograph was taken randomly from each of four peripheral areas $3 \mathrm{~mm}$ from the optic nerve head. RBPMS-positive cells were counted manually in a masked fashion and presented as cells per millimeter squared.

\section{RNA-seq of purified RGCs}

For viral transduction of E18 RGCs for RNA-seq, $2.5 \times 10^{5} \mathrm{RGC} /$ well were plated on PDL/laminin-coated six-well plates in quadruplicates. Four hours after plating, 1.5- $\mu$ l AAV $\left(2 \times 10^{13} \mathrm{vg} / \mathrm{ml}\right)$ was added to cultured cells at a MOI of $\sim 10^{5} \mathrm{vg} / \mathrm{cell}$. Full medium changes were performed 5.5 and $24 \mathrm{~h}$ after virus exposure. Total RNA was extracted using the RNEasy kit (QIAGEN) $72 \mathrm{~h}$ after plating. Library construction and next generation sequencing was performed at Genewiz on three RNA samples $(500 \mathrm{ng} / \mathrm{sample})$ in duplicates. The samples were 


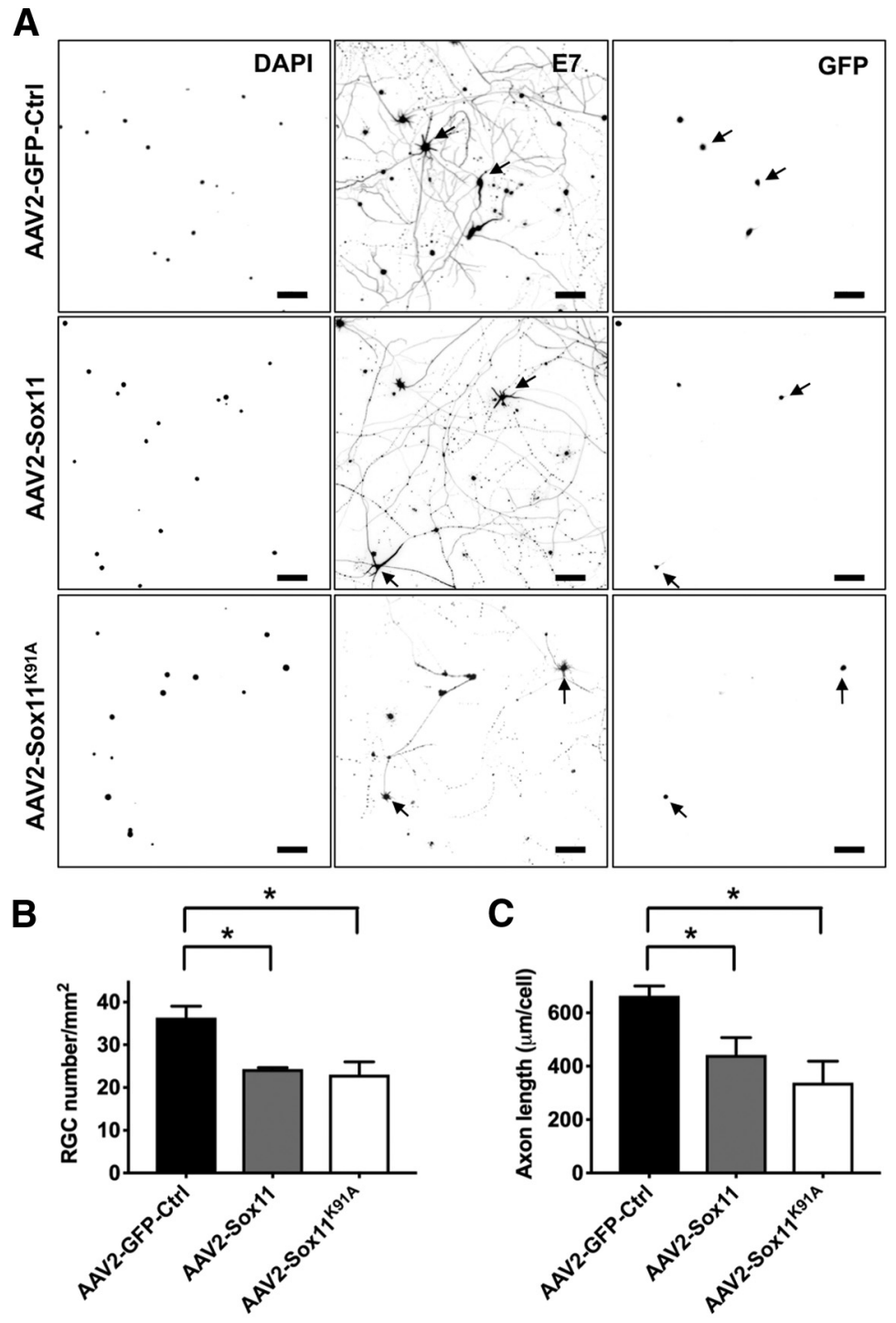

Figure 2. Sox11 and Sox $11^{\mathrm{K} 91 \mathrm{~A}}$ decrease RGC viability and axon outgrowth in vitro. Primary RGCs were transduced with Sox11 or control AAVs as marked, cultured for $3 \mathrm{~d}$, and immunostained for $\beta$-III tubulin (E7) and GFP to identified transduced neurons, and counterstained with the nuclear dye DAPI $(\boldsymbol{A})$. Exogenous expression of either Sox 11 or Sox $11^{\mathrm{K} 91 \mathrm{~A}}$ reduced cell survival $(\boldsymbol{B})$ and axon outgrowth $(\boldsymbol{C})$ in primary RGCs $\left(N \geq 3\right.$ experimental replicates, ${ }^{*} p<0.05$, by one-way ANOVA and post hoc $t$ test with Tukey correction; mean \pm SEM shown; scale bar: $200 \mu \mathrm{m})$.

analyzed in two lanes using an Illumina $2000 \mathrm{HI}$-seq machine that generated between 65 and 91 million reads per sample.

The RNA-seq reads were aligned to the mouse genome mm10 with the RNA computational pipeline on the DNAnexus cloud computing platform comprised of the STAR alignment package and RSEM counting algorithm. Each sample (control, SOX11 wild type, and SOX $11^{\mathrm{k} 91 \mathrm{~A}}$ ) had two replicates. The differentially expressed genes were called by using limma-voom in R/BioC on the RNA-seq replicates, and the genes with a FDR $<0.05$ and an absolute fold change $(F C)>1.2$ were considered for down-stream analysis. The functional enrichment of differentially expressed genes was computed in enrichR, and volcano plots were displayed in R. The RNA-seq data are uploaded in raw format to GEO (accession GSE160627, token wxexuqkmjrcjdgf).

\section{Statistical analysis}

Results are shown as the mean \pm SEM of at least three experiments. Data were analyzed by ANOVA with a post hoc $t$ test with Tukey correction and/or unpaired $t$ test with $p<0.05$ considered significant.

\section{Results}

\section{Sox $11^{\text {K91A }}$ prevents Sox 11 SUMOylation}

To investigate the effects of Sox11 in vivo, we first designed AAV-backbone plasmids encoding Sox11 and Sox $11^{\mathrm{K} 91 \mathrm{~A}}$ and verified protein expression level after $3 \mathrm{~d}$ of coculture in HEK 293 cells and hippocampal neurons by immunostaining (Fig. 1A) and Western blotting (Fig. 1B,C). A total of $90 \%$ and $82 \%$ of cells were transduced by of Sox 11 and Sox $11^{\mathrm{K} 91 \mathrm{~A}} \mathrm{AAVs}$, respectively (Fig. 1A). Similar 
levels of exogenous Sox11 and GFP proteins were detected in HEK 293 cells $\left(\right.$ Sox $11^{\mathrm{K} 91 \mathrm{~A}}$ at 1.08 -fold expression of Sox 11; Fig. 1B) and hippocampal neurons (Sox11 and Sox $11^{\mathrm{K} 1 \mathrm{~A}}$ at 1.02 -fold and 0.98-fold of control AAV; Fig. $1 C)$, respectively. To verify whether Sox $11^{\mathrm{K} 91 \mathrm{~A}}$ is associated with less SUMOylation in primary neurons, we expressed wild-type Sox11 or Sox $11^{\mathrm{K} 91 \mathrm{~A}}$ in purified RGC cultures and observed fewer higher molecular weight moieties with Sox $11^{\mathrm{K} 91 \mathrm{~A}}$ than with wild-type Sox11 (Fig. 1D). Thus, consistent with our previous findings with a different Sox11 construct (Chang et al., 2017), mutating the K91 residue decreases Sox11 SUMOylation.

\section{Sox11 and Sox $11^{\mathrm{K} 91 \mathrm{~A}}$ decrease RGC survival and axon growth in vitro}

We next examined Sox 11 versus Sox $11^{\mathrm{K} 91 \mathrm{~A}}$ effects on RGC survival and axon outgrowth in vitro (Fig. 2A). Compared with AAV2-GFP-Ctrl, AAV2-Sox11 and AAV2Sox $11^{\mathrm{K} 91 \mathrm{~A}}$ significantly reduced RGC viability (Fig. 2B) and axon outgrowth (Fig. 2C) after $3 \mathrm{~d}$ in vitro. However, we did not observe significant phenotype differences between AAV2-Sox11-treated and AAV2-Sox11 ${ }^{\mathrm{K} 91 \mathrm{~A}}$-treated groups for either phenotype. We repeated this in vitro study at 5-fold lower cell density and found a similar trend (data not shown). Thus, Sox11 reduces RGC survival and axon growth in vitro, although these data suggest that point mutation of Sox11 on K91 does not amplify these effects, at least in vitro.

\section{Sox $11^{\text {K91A }}$ more strongly promotes both RGC death and optic nerve regeneration in vivo}

To test whether Sox $11^{\mathrm{K} 91 \mathrm{~A}}$ differs from Sox11 in vivo, we intravitreally injected AAVs into normal (uninjured) host eyes, or two weeks before inducing a retrobulbar optic nerve crush injury (Fig. $3 A$ ). We found that AAV2-Sox11 was associated with increased RGC death in vivo in both normal eyes (Fig. 3B) or eyes subjected to optic nerve injury (Fig. 3 C), consistent with our in vitro data (Fig. 2) and that from a previous study (Norsworthy et al., 2017). Sox $11^{\mathrm{K} 91 \mathrm{~A}}$ more strongly promoted RGC death in vivo in both conditions (Fig. 3). We also examined axon regeneration in the mouse optic nerve crush model, using anterograde tracing with CTB (Fig. 4A). Exogenous Sox11 expression increased the number of $\mathrm{CTB}^{+}$regenerating axons, and Sox $11^{\mathrm{K} 91 \mathrm{~A}}$ promoted significantly more optic nerve axon regeneration than Sox11 (Fig. 4B). Thus, blocking SUMOylation at K91 potentiates axon regeneration in adult RGCs, similar to the potentiation of RGC differentiation during development.

\section{Sox11 and Sox11 ${ }^{\mathrm{K} 91 \mathrm{~A}}$ differently regulate RGC gene expression}

Finally, to explore potential mechanisms by which Sox 11 or Sox $11^{\mathrm{K} 91 \mathrm{~A}}$ differentially affect survival and axon growth, we compared transcriptome changes in RGCs in vitro after exogenous expression, using deep sequencing. We first observed that Sox11 and Sox $11^{\mathrm{K} 91 \mathrm{~A}}$ were upregulated 41 -fold and 33 -fold $(p=5.9 \mathrm{E}-07$ and $p=4.4 \mathrm{E}-03$, respectively) in transduced cultures. Exploring gene set
A
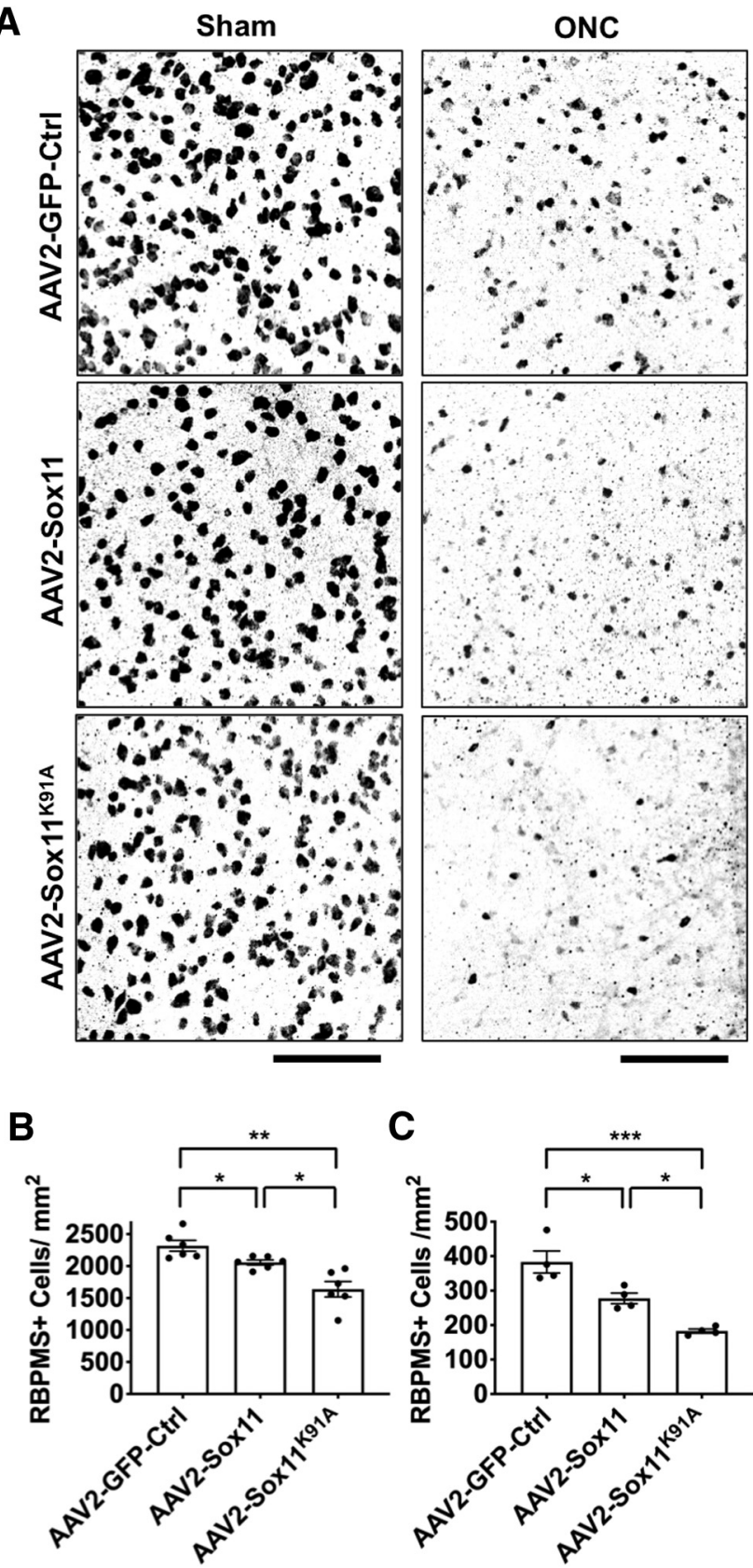

Figure 3. Exogenous Sox $11^{\mathrm{K} 91 \mathrm{~A}}$ leads to more RGC death than Sox11 in vivo. Control AAV2-GFP-Ctrl, AAV2-Sox11, or AAV2Sox $11^{\mathrm{K} 91 \mathrm{~A}}$ were injected intravitreally in control eyes and in eyes two weeks before optic nerve crush. Two weeks after injection in controls, or two weeks after optic nerve crush (four weeks after injection), eyes were harvested and retinas flat-mounted and immunostained against RGC-specific marker RBPMS $(\boldsymbol{A})$. Both Sox11 and Sox $11^{\mathrm{K} 91 \mathrm{~A}}$ significantly increased RGC death in sham $(\boldsymbol{B})$ and optic nerve crush $(\boldsymbol{C})$ eyes, with Sox $11^{\mathrm{K} 91 \mathrm{~A}}$ showing significantly greater effect than wild-type Sox11 ( $N \geq 4$ experimental replicates, ${ }^{*} p<0.05,{ }^{* *} p<0.01$, ${ }^{* *} p<0.001$, by one-way ANOVA with post hoc $t$ test with Tukey correction; mean \pm SEM shown; scale bar: $100 \mu \mathrm{m})$. 
A

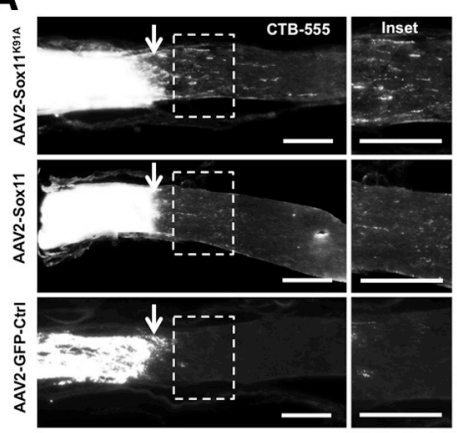

B

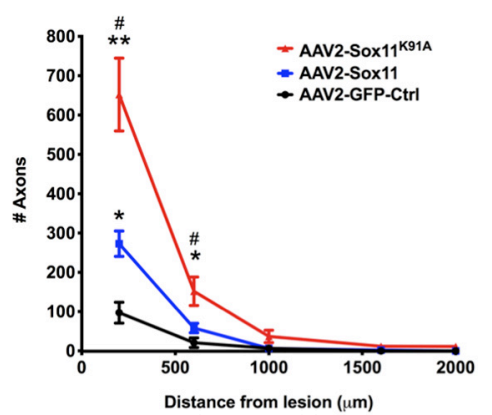

Figure 4. Sox $11^{\mathrm{K} 91 \mathrm{~A}}$ promotes more axon regeneration than Sox11 in vivo. Intravitreal AAV2 injection was performed as in Figure 3. Regenerating axons were visualized by CTB-555 injection anterograde labeling $2 \mathrm{~d}$ before euthanasia $(\boldsymbol{A})$. Both Sox11 and Sox $11^{\mathrm{K} 91 \mathrm{~A}}$ significantly promoted more short distance $(200$ and $600 \mu \mathrm{m})$ axon regeneration than controls, with Sox $11^{\mathrm{K} 91 \mathrm{~A}}$ showing significantly greater effect than wild-type Sox11 (B). The arrows indicate crush sites. $N \geq 5$ animals per group, * compares with AAV2-GFP-Ctrl group; \# compares with AAV2-Sox11 group; ${ }^{*} p<0.05$ versus control, ${ }^{* \star} p<0.01$ versus control, \#p $<0.05$ versus AAV2-Sox11, by one-way ANOVA with post hoc $t$ test with Tukey correction. Mean \pm SEM shown. Scale bar: $200 \mu \mathrm{m}$.

enrichment analyses with enrichR, we found that both Sox 11 and Sox $11^{\mathrm{K} 91 \mathrm{~A}}$ upregulated signaling pathways involved in axongenesis, nervous system development, axon guidance, neuron migration and generation of neurons (Fig. 5A). Interestingly, Sox $11^{\mathrm{K} 91 \mathrm{~A}}$ showed stronger effects than Sox11 in genes related to neuronal generation, migration, and axongenesis, but weaker influences on axon guidance and nervous system development in the nucleus. These data suggest the hypothesis that Sox11 in nucleus versus SUMOylated Sox11 in the cytoplasm may regulate neuronal and axonal physiology by different mechanisms. We also detected differentially expressed genes associated with RGC subtype specificity and observed for example that RGC subtype markers Opn4 (melanopsin) and Spp1 were downregulated by Sox11 (Fig. 5B). The downregulation of Opn4 and Spp 1 was further confirmed by qRT-PCR (Fig. 5C). This is the first report of the Opn4+ intrinsically photosensitive (ip)RGC subtype being influenced by Sox11. Sox $11^{\mathrm{K} 91 \mathrm{~A}}$ showed a stronger effect than Sox11 on Spp 1 but not Opn4, suggesting different susceptibilities of RGC subtypes to Sox $11^{\mathrm{K} 91 \mathrm{~A}}$.

\section{Discussion}

Taken together, these data indicate three important findings. First, our data reveal that overexpression of a non-SUMOylatable point mutant of Sox11 shows stronger influences than WT Sox11 on decreasing RGC survival but promoting axon regeneration. These data extend our previous study that deSUMOlyated Sox11 translocates into the nucleus to more potently regulate RGC differentiation (Chang et al., 2017). SUMO conjugation acts to regulate many transcription factors, including other Sox family proteins (Williams et al., 2020). Ubiquitin-conjugating enzyme 9 (Ubc9) can interact with Sox4 in the nucleus and repress Sox4's transcriptional activity, even without its SUMO-1 conjugating capability (Pan et al., 2006). Protein inhibitor of activated STAT (PIAS), known as E3 SUMO-protein ligase, is also known to facilitate protein SUMOylation (Johnson and Gupta, 2001). It will be interesting to dissect out which SUMO ligase(s) are responsible for Sox11 SUMOylation, e.g., through an siRNA or CRISPR screen, in future studies.

Surprisingly, both Sox 11 and Sox $11^{\mathrm{K} 91 \mathrm{~A}}$ suppressed axon outgrowth in vitro but promoted axon regeneration in vivo after optic nerve crush, with Sox $11^{\mathrm{K} 91 \mathrm{~A}}$ consistently showing strong effects in either direction than WT Sox11. Despite this difference, we found that signaling pathways involved in axongenesis are upregulated by Sox 11 and Sox $11^{\mathrm{K} 91 \mathrm{~A}}$. RGC density in culture strongly affects axon outgrowth (Goldberg et al., 2002), thus a component of this contradictory data could be explained by low cell density in axon outgrowth assays. In addition, the cell-cell interaction with other retinal cell types in vivo is absent in the culture in vitro. Regarding cell-type specificity, a previous study showed that Sox 11 preferentially kills $\alpha$-RGCs and other RGC subtypes (Norsworthy et al., 2017), and these subtypes may normally extend longer neurites in vitro, a hypothesis that could be tested using the various strains of fluorescently labeled RGC subtypes (Hong et al., 2011; Dhande and Huberman, 2014). It is also possible that Sox11 may regulate axon growth in the young RGCs studied in culture by different mechanisms that the adult RGCs studied for axon regeneration in vivo.

Second, we identified candidate signaling pathways regulated by Sox11 and Sox11 $11^{\mathrm{K} 1 \mathrm{~A}}$. In the RNA-seq analysis, many signaling pathways related to axonal and neuronal physiology were regulated by Sox 11 expression. For example, we found that $\operatorname{TGF} \beta$ R2, a receptor upstream of $\mathrm{Smad} 2 / 3$ signaling, was also downregulated by Sox11 (Fig. 5B). These data are interesting in light of previous data showing that suppression of Smad2 expression promotes axon growth in an in vitro assay (Hannila et al., 2013), and suggest the hypothesis that Sox11 may promote axon regeneration by regulating TGF/Smad signaling, a question to test in future studies. We also detected upregulation of MEF2C expression in Sox11-treated RGCs (Fig. 5B), consistent with our and others' data that MEF2 genes promote RGC death in RGCs (Welsbie et al., 2017), 
A

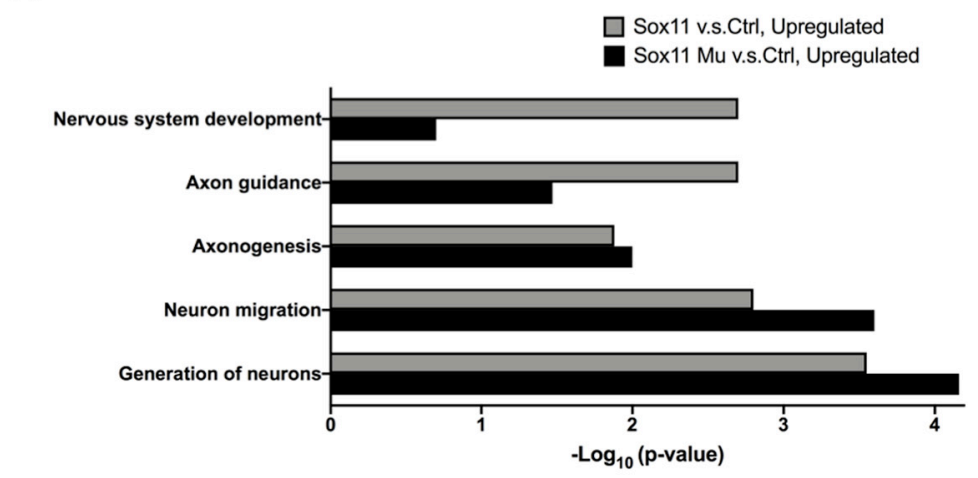

B

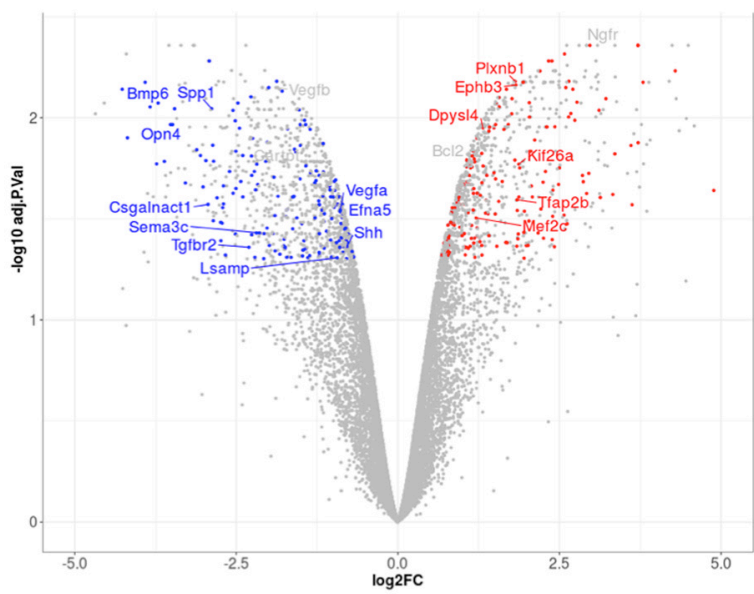

C
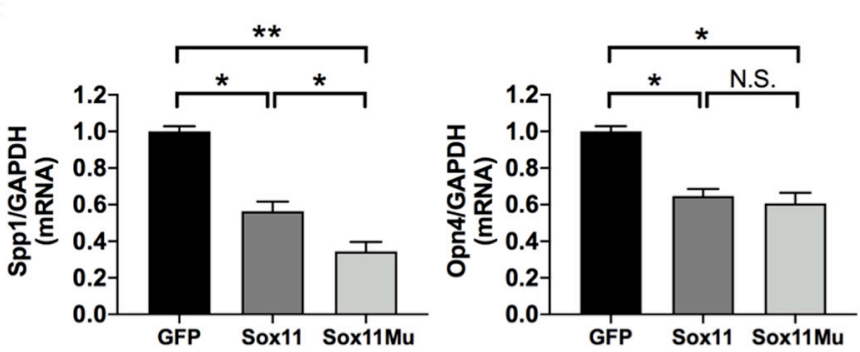

Figure 5. Gene regulation by Sox11 and Sox $11^{\mathrm{K} 91 \mathrm{~A}}$ in primary RGCs. A, Sox11 and Sox $11^{\mathrm{K} 91 \mathrm{~A}}$ upregulate several signaling pathways related to neuronal and axon growth. $\boldsymbol{B}, \mathrm{A}$ volcano plot highlighting selected genes that are more downregulated by Sox $11^{\mathrm{K} 91 \mathrm{~A}}$ than by Sox11 (in blue, 173 genes) and selected genes that are more upregulated by Sox $11^{\mathrm{K} 91 \mathrm{~A}}$ than by Sox11 (in red, 181 genes). C, Spp1 and Opn4 were significantly downregulated in Sox11-treated and Sox11 K91A -treated groups, confirmed by qRT-PCR $\left(N=3,{ }^{*} p<0.05,{ }^{* *} p<0.01\right.$; N.S., no significant difference, by one-way ANOVA with post hoc $t$ test with Tukey correction; mean \pm SEM shown).

and overexpression of MEF2C induces apoptosis in other cells (Bao et al., 2019). On the other hand, expression of anti-apoptosis gene Bclll was upregulated (Fig. 5B), consistent with a compensatory response against apoptosis.

Finally, our data add to the literature on RGC subtypespecific regulation. The presence of resilient and susceptible populations of RGCs has been identified based on their different ability to survive or regenerate axons following optic nerve injury (Norsworthy et al., 2017; Tran et al., 2019). Based on Sox11's downregulation of the photopigment gene melanopsin (encoded by Opn4), Sox11 may preferentially lead to the death of another RGC subtype, ipRGCs (Berson et al., 2002; Hattar et al., 2002). We also found that Sox11 downregulates Spp1 gene expression in RGCs, which is consistent with the previous study that Sox 11 leads to death of $\alpha$-RGCs (a subtyped defined in part by Spp1 expression). Very little is known about how transcription factors like Sox 11 may regulate specific subsets of RGCs or their expression of genes like Spp1 or Opn4, presumably leveraging subtype-specific co-factors or epigenomic access. Since E18 RGC culture was used for RNA-seq, it is possible that Sox11 alters some newborn RGCs toward nonipRGC and non- $\alpha$-RGC cell fates. Understanding how Sox11 specifically targets $\alpha$-RGC and ipRGC would be 
an interesting future direction that may be better served by future experiments leveraging single-cell RNA-seq (scRNA-seq; Tran et al., 2019). Certainly, placing Sox11 into a molecular regulatory pathway and better understanding its effects in differentially regulating survival and axon regeneration in different RGC subtypes could lead to a more potent therapeutic strategy for axon regeneration.

\section{References}

Badea TC, Cahill H, Ecker J, Hattar S, Nathans J (2009) Distinct roles of transcription factors brn3a and brn3b in controlling the development, morphology, and function of retinal ganglion cells. Neuron 61:852-864

Bao Q, Jia H, A R, Cao Z, Zhang Y (2019) MiR-210 inhibits hypoxiainduced apoptosis of smooth muscle cells via targeting MEF2C. Int J Clin Exp Pathol 12:1846-1858.

Barres BA, Silverstein BE, Corey DP, Chun LL (1988) Immunological, morphological, and electrophysiological variation among retinal ganglion cells purified by panning. Neuron 1:791-803.

Bei F, Lee HHC, Liu X, Gunner G, Jin H, Ma L, Wang C, Hou L, Hensch TK, Frank E, Sanes JR, Chen C, Fagiolini M, He Z (2016) Restoration of visual function by enhancing conduction in regenerated axons. Cell 164:219-232.

Benowitz LI, He Z, Goldberg JL (2017) Reaching the brain: advances in optic nerve regeneration. Exp Neurol 287:365-373.

Berson DM, Dunn FA, Takao M (2002) Phototransduction by retinal ganglion cells that set the circadian clock. Science 295:10701073.

Boczek T, Cameron EG, Yu W, Xia X, Shah SH, Castillo Chabeco B, Galvao J, Nahmou M, Li J, Thakur H, Goldberg JL, Kapiloff MS (2019) Regulation of neuronal survival and axon growth by a perinuclear cAMP compartment. J Neurosci 39:5466-5480.

Cameron EG, Xia X, Galvao J, Ashouri M, Kapiloff MS, Goldberg JL (2020) Optic nerve crush in mice to study retinal ganglion cell survival and regeneration. Bio Protoc 10:e3559.

Chang KC, Hertz J (2017) SoxC transcription factors in retinal development and regeneration. Neural Regen Res 12:1048-1051.

Chang KC, Hertz J, Zhang X, Jin XL, Shaw P, Derosa BA, Li JY, Venugopalan $P$, Valenzuela DA, Patel RD, Russano KR, Alshamekh SA, Sun C, Tenerelli K, Li C, Velmeshev D, Cheng Y, Boyce TM, Dreyfuss A, Uddin MS, et al. (2017) Novel regulatory mechanisms for the SoxC transcriptional network required for visual pathway development. J Neurosci 37:4967-4981.

Chang KC, Sun C, Cameron EG, Madaan A, Wu S, Xia X, Zhang X, Tenerelli K, Nahmou M, Knasel CM, Russano KR, Hertz J, Goldberg JL (2019) Opposing effects of growth and differentiation factors in cell-fate specification. Curr Biol 29:1963-1975.e5.

Dhande OS, Huberman AD (2014) Retinal ganglion cell maps in the brain: implications for visual processing. Curr Opin Neurobiol 24:133-142.

Gill G (2005) SUMO changes Sox for developmental diversity. Mol Cell 20:495-496.

Goldberg JL, Guido W; Agi Workshop Participants (2016) Report on the national eye institute audacious goals initiative: regenerating the optic nerve. Invest Ophthalmol Vis Sci 57:1271-1275.

Goldberg JL, Espinosa JS, Xu Y, Davidson N, Kovacs GT, Barres BA (2002) Retinal ganglion cells do not extend axons by default: promotion by neurotrophic signaling and electrical activity. Neuron 33:689-702.

Hannila SS, Siddiq MM, Carmel JB, Hou J, Chaudhry N, Bradley PM, Hilaire M, Richman EL, Hart RP, Filbin MT (2013) Secretory leukocyte protease inhibitor reverses inhibition by CNS myelin, promotes regeneration in the optic nerve, and suppresses expression of the transforming growth factor- $\beta$ signaling protein Smad2. J Neurosci 33:5138-5151.

Hattar S, Liao HW, Takao M, Berson DM, Yau KW (2002) Melanopsin-containing retinal ganglion cells: architecture, projections, and intrinsic photosensitivity. Science 295:1065-1070.

Hong YK, Kim IJ, Sanes JR (2011) Stereotyped axonal arbors of retinal ganglion cell subsets in the mouse superior colliculus. J Comp Neurol 519:1691-1711.

Jiang Y, Ding Q, Xie X, Libby RT, Lefebvre V, Gan L (2013) Transcription factors SOX4 and SOX11 function redundantly to regulate the development of mouse retinal ganglion cells. J Biol Chem 288:18429-18438.

Johnson ES, Gupta AA (2001) An E3-like factor that promotes SUMO conjugation to the yeast septins. Cell 106:735-744.

Kuwajima T, Soares CA, Sitko AA, Lefebvre V, Mason C (2017) SoxC transcription factors promote contralateral retinal ganglion cell differentiation and axon guidance in the mouse visual system. Neuron 93:1110-1125.e5.

Meyer-Franke A, Tropak MB, Roder JC, Fischer P, Beyreuther K, Probstmeier R, Schachner M (1995) Functional topography of myelin-associated glycoprotein. II. Mapping of domains on molecular fragments. J Neurosci Res 41:311-323.

Norsworthy MW, Bei F, Kawaguchi R, Wang Q, Tran NM, Li Y, Brommer B, Zhang Y, Wang C, Sanes JR, Coppola G, He Z (2017) Sox11 expression promotes regeneration of some retinal ganglion cell types but kills others. Neuron 94:1112-1120.e4.

Pan X, Li H, Zhang P, Jin B, Man J, Tian L, Su G, Zhao J, Li W, Liu H, Gong W, Zhou T, Zhang X (2006) Ubc9 interacts with SOX4 and represses its transcriptional activity. Biochem Biophys Res Commun 344:727-734

Roger JE, Nellissery J, Kim DS, Swaroop A (2010) Sumoylation of bZIP transcription factor NRL modulates target gene expression during photoreceptor differentiation. J Biol Chem 285:2563725644 .

Stankowska DL, Minton AZ, Rutledge MA, Mueller BH 2nd, Phatak NR, He S, Ma HY, Forster MJ, Yorio T, Krishnamoorthy RR (2015) Neuroprotective effects of transcription factor Brn3b in an ocular hypertension rat model of glaucoma. Invest Ophthalmol Vis Sci 56:893-907.

Struebing FL, Wang J, Li Y, King R, Mistretta OC, English AW, Geisert EE (2017) Differential expression of Sox11 and Bdnf mRNA isoforms in the injured and regenerating nervous systems. Front Mol Neurosci 10:354.

Tran NM, Shekhar K, Whitney IE, Jacobi A, Benhar I, Hong G, Yan W, Adiconis X, Arnold ME, Lee JM, Levin JZ, Lin D, Wang C, Lieber CM, Regev A, He Z, Sanes JR (2019) Single-cell profiles of retinal ganglion cells differing in resilience to injury reveal neuroprotective genes. Neuron 104:1039-1055.e12.

Wang Q, Zhuang P, Huang H, Li L, Liu L, Webber HC, Dalal R, Siew $L$, Fligor $\mathrm{CM}$, Chang KC, Nahmou M, Kreymerman A, Sun $\mathrm{Y}$, Meyer JS, Goldberg JL, Hu Y (2020) Mouse $\gamma$-synuclein promotermediated gene expression and editing in mammalian retinal ganglion cells. J Neurosci 40:3896-3914.

Welsbie DS, Mitchell KL, Jaskula-Ranga V, Sluch VM, Yang Z, Kim J, Buehler E, Patel A, Martin SE, Zhang PW, Ge Y, Duan Y, Fuller J, Kim BJ, Hamed E, Chamling X, Lei L, Fraser IDC, Ronai ZA, Berlinicke CA, et al. (2017) Enhanced functional genomic screening identifies novel mediators of dual leucine zipper kinase-dependent injury signaling in neurons. Neuron 94:1142-1154.e6.

Williams CAC, Soufi A, Pollard SM (2020) Post-translational modification of SOX family proteins: key biochemical targets in cancer? Semin Cancer Biol 67:30-38. 